\title{
A PARRHESÍA NA CONSTITUIÇÃO DO SUJEITO ÉTICO EM M. FOUCAULT: ANÁLISE DOS CURSOS NO COLLÈGE DE FRANCE, 1982-1983.
}

\author{
PARRHESÍA THE SUBJECT OF THE CONSTITUTION ETHICAL M. FOUCAULT: ANALYSIS OF COURSES \\ AT THE COLLÈGE DE FRANCE, 1982-1983.
}

\author{
Carlos Renato Moiteiro* \\ Evandro Sousa da Mata**
}

\section{RESUMO}

No conjunto das obras do filósofo francês Michel Foucault, a constituição do sujeito na modernidade constitui uma de suas principais preocupações e fio condutor de sua pesquisa. Sob o prisma de acontecimentos singulares, situados espacial e historicamente, a emergência de uma subjetividade na construção do pensamento ocidental é tomada pelo autor sempre em sua relação com a verdade - ou melhor, com as formas de dizer a verdade sobre o sujeito. Tal perspectiva apresenta-se de forma constante nos cursos do autor: enquanto, num primeiro momento, ocupa-se de examinar a relação estabelecida entre sujeito, saber e verdade, segundo uma arqueologia dos jogos de verdade que regem os saberes de determinada epistémê, e que constituem o sujeito no interior do discurso, posteriormente passará a investigar as práticas que permitem estabelecer relações entre o sujeito e a verdade mediadas por mecanismos os mais diversificados de poder; dá, assim, origem a uma genealogia das práticas e mecanismos de poder, que integram o discurso e o estende em formas concretas de subjetivação. Como desdobramento último desta genealogia das práticas de subjetivação, Foucault entrevê, na história das relações do sujeito consigo mesmo - de modo especial, nos contornos diversos que tais relações assumiram durante a Antiguidade -, o modo pelo qual o indivíduo tem acesso à verdade, mediante as operações que realiza em si. No presente trabalho, tomaremos como objeto de análise a obrigação de dizer a verdade - a saber, a parrhesía -, tal como este conceito é apresentado nos cursos de 1982 (A hermenêtica do sujeito) e 1983 (O governo de si e dos outros) no Collège de France, como elemento articulador entre verdade e práticas de si, analisando o caráter de exigência de sua proposição, enquanto constituidora de um ethos do sujeito da antiguidade, bem como suas implicações no âmbito da experiência política.

PALAVRAS-CHAVE: Parrhesía. Veridicção. Subjetividade. Práticas. Autopoiese.

\footnotetext{
${ }^{*}$ Mestre em Filosofia. Doutorando em Filosofia pela Pontifícia Universidade Católica do Paraná (PPGF-PUCPR); docente e coordenador do Eixo de Formação humana na referida instituição. E-mail: carlos.moiteiro @ outlook.com.

${ }^{* *}$ Bacharel em Filosofia pela FAVI - Faculdade Vicentina de Filosofia (Curitiba-PR).

E-mail: evandrodamata40@ hotmail.com.
} 


\section{ABSTRACT}

In the set of the work of French philosopher Michel Foucault, the constitution of the subject in modernity is one of his main concerns and common thread of his research. From the perspective of singular happenings (événements), spatially and historically located, the emergence of subjectivity in the construction of Western thought is taken by the author always in its relation to the truth - or rather, the manners to tell the truth about the subject. Such perspective presents constantly in the author's courses: while, at first, he is concerned with to examine the relation between subject knowledge and truth, according to an archeology of the games of truth that govern knowledges of a particular episteme and which constitute the subject within the discourse, subsequently he investigates the practices which allow to establish relations between the subject and the truth mediated by the most diverse power mechanisms; thus gives rise to a genealogy of practices and mechanisms of power, integrating the speech and extending it into concrete forms of subjectification. As a last unfolding of this genealogy of practices of subjectification, Foucault glimpses in the history of relations of the subject with himself - in particular, the various contours that such relationships assumed in Antiquity - the manner in which the individual has access to the truth by operations that one performs himself. In this article, we will take as object of analysis the obligation to tell the truth - namely, parrhesía - as this concept is presented in the courses at Collège de France in 1982 (The Hermeneutics of the Subject) and 1983 (The Government of Self and Others), as an articulator element between truth and practices of the self, analyzing the requirement character of its proposition, while constitutor of the ancient subject's ethos, and its implications in the context of political experience.

KEY WORDS: Parrhesia. Veridiction. Subjectivity. Practices. Autopoiesis.

\section{INTRODUÇÃO.}

A despeito da controvérsia acerca das razões que levaram Foucault à análise da Antiguidade em seus cursos a partir de 1980, é preciso ter em mente a visão prospectiva do autor sobre sua própria obra, quando afirma ter como objetivo a realização de um diagnóstico do presente. A história genealógica do sujeito moderno, que o filósofo francês analisa, é uma "história crítica dos jogos de verdade" (CANDIOTTO, 2013, p. 19) e desse mesmo "sujeito", segundo um conjunto muito amplo de suas constituições, tal como assumido pelo autor: "Eu procuro diagnosticar, realizar um diagnóstico do presente: dizer o que somos hoje e o que 
Autor: A parrhesía na constituição do sujeito ético em M. Foucault: análise dos cursos no Collège de France, 19821983.

significa, hoje, dizer o que nós dizemos. Esse trabalho de escavação sob nossos pés caracteriza, desde Nietzsche, o pensamento contemporâneo, e nesse sentido eu posso me declarar filósofo" (FOUCAULT, 2014, p. 34).

O problema da gestão dos indivíduos e das populações foi desenvolvido no estudo do governo dos homens, da chamada arte de governar: no poder pastoral e na razão de Estado (MACHADO, 2012). Na modernidade, tem-se a mentalidade de que se governa muito pouco e, por isso, deve-se governar mais: vivemos numa época em que a governamentalidade permeia e conduz a nossa vida. A problemática da condução, da gestão de indivíduos e populações, foi consagrada no estudo da governamentalidade: o controle que a política, que o poder, através de procedimentos de Estado, tem sobre a vida dos indivíduos constituídos no fenômeno população ${ }^{1}$. Do estudo do governo dos outros, do governo de uns sobre outros, emerge na genealogia foucaultiana a preocupação com o governo de si.

Desde a publicação da Histoire de la sexualité I (HS), La volonté de savoir, em 1976, o filósofo deslocou seu diagnóstico de uma genealogia do governo dos outros para uma análise do governo de si - tal como encontrada nos cursos do Collège de France pós-1980 e nos volumes II e III de HS, ambos de 1984. Em L'usage des plaisirs, sobre sua opção por “[...] reorganizar todo o estudo em torno da lenta formação, durante a Antiguidade, de uma hermenêutica de si", Foucault (2014c, p. 11-12) afirma (grifos nossos):

[...] foi por este último partido que optei ao pensar que, afinal de contas, aquilo a que me atenho - a que me ative há tantos anos - é a tarefa de evidenciar alguns elementos que possam servir para uma história da verdade. Uma história que não seria aquela do que poderia haver de verdadeiro nos conhecimentos; mas uma análise dos "jogos da verdade", dos jogos entre o verdadeiro e o falso, através dos quais o ser se constitui historicamente como experiência, isto é, como podendo e devendo ser pensado. Através de quais jogos da verdade o homem se dá seu ser próprio a pensar quando se percebe como louco, quando se olha como doente, quando reflete sobre si como ser vivo, ser falante e ser trabalhador, quando ele se julga e se pune enquanto criminoso? Através de quais jogos da verdade ${ }^{2}$ o ser humano se reconheceu como homem de desejo?

\footnotetext{
${ }^{1}$ Os cursos dados por Foucault no Collège de France, entre 1975 à 1979, ocupam-se da questão política nas táticas e técnicas da governamentalidade. Sobre esta arte de governar, assevera ele (FOUCAULT, 2012, p. 430): “desde o século XVIII, vivemos na era da governamentalidade. Governamentalização do Estado, que é um fenômeno particularmente astucioso, pois se efetivamente os problemas da governamentalidade, as técnicas de governo se tornaram a questão política fundamental e o espaço real da luta política, a governamentalização do Estado foi o fenômeno que permitiu ao Estado sobreviver". O curso de 1980 indica na sua própria intitulação o seu objetivo de análise: "Du gouvernament des vivants" ("Do governo dos vivos") - a "arte de governar" os vivos.

2 "Jeux de verité" (como no texto original de "L'usage des plaisirs", de 1984) é, e deve ser, traduzido por "jogos de verdade" (e não "jogos da verdade", como o faz a tradutora desta edição de 2014), o que faz toda a diferença no
} 
Ora, se é certo que determinadas temáticas surgidas em uma parte ou outra da obra de Foucault não puderam ser alvo de pesquisa mais aprofundada - como ele mesmo admite (FOUCAULT, 2010b, p. 7-8) -, a que agora se apresenta, por outro lado, tornar-se-á o centro de toda a produção do autor, de 1980 até sua morte, e que pode ser resumida na seguinte questão: através de quais práticas o sujeito pôde estabelecer uma plena relação de verdade consigo mesmo e com os outros? No curso de 1981, Subjectivité et vérité, Foucault inicia sua pesquisa sobre os modos constituídos do "[...] conhecimento de si e sobre sua história: como o sujeito se estabeleceu, em diferentes momentos e em diferentes contextos institucionais, como um objeto de conhecimento possível, desejável ou até indispensável?" (FOUCAULT, 2014, p. 349). Para que o sujeito produza a verdade que há em si mesmo, para que ele se conheça, faz-se necessárias algumas práticas: são as técnicas de si o fio condutor deste empreendimento de 1981 . O ponto de partida será o Alcibíades de Platão, diálogo em que se apresentam as noções de epiméleia heautô̂ (o cuidado de si) e gnôthi seautón (o conhecimento de si) como preocupações fundamentais do trabalho filosófico do sujeito para que se tenha o acesso à verdade. A história da subjetividade que faz Foucault, antes tratada pela análise das positividades da loucura, da doença, dos saberes, da delinquência e das formas de governamentalidade, agora concentrar-se-á na história do cuidado e das técnicas de si. Neste curso, porém, a genealogia da ética se "delimita" no regime dos aphrodisia (que, muito mal, traduzimos para "sexualidade"), na cultura helênica e romana. As relações aí estabelecidas se efetuam no conjunto subjetividadesexualidade-verdade (FOUCAULT, 2014, p. 349-351).

Já no curso de1982, L’Herméneutique du sujet - inteiramente dedicado à história do cuidado de si, a saber, o modo pelo qual o sujeito constitui a si mesmo, o seu ethos - o filósofo assim assume seu projeto (FOUCAULT, 2011b, p. 4): “a questão que apreciaria abordar neste ano é a seguinte: em que forma de história foram tramadas, no Ocidente, as relações, que não estão suscitadas pela prática ou pela análise histórica habitual, entre estes dois elementos, o 'sujeito' e a 'verdade"”. Do projeto de uma história da subjetividade, em sua relação com a verdade, o autor se desloca para uma história da "hermenêutica de si" (FOUCAULT, 2011b, p.

texto de Foucault: uma vez que o sujeito é sujeito de verdade, capaz de verdade (e não um sujeito da verdade, no sentido em que ele seria objeto e, portanto, objetivado por uma verdade que seria "autônoma" a ele, cabendo a ela prescrever tal sujeito). 
Autor: A parrhesía na constituição do sujeito ético em M. Foucault: análise dos cursos no Collège de France, 19821983.

443), ocupando-se em analisar no que consistia o cuidado de si enquanto "fenômeno cultural de conjunto" e como "acontecimento no pensamento". Afirma (FOUCAULT, 2011b, p. 11):

Parece-me que a aposta, o desafio que toda história do pensamento deve suscitar, está precisamente em apreender o momento em que um fenômeno cultural, de dimensão determinada, pode efetivamente constituir, na história do pensamento, um momento decisivo no qual se acha comprometido até mesmo nosso modo de ser de sujeito moderno.

Foucault volta seu olhar à Antiguidade para captar o momento em que surge este "fenômeno" - o cuidado de si - na preocupação filosófica e enquanto um "fenômeno cultural" de conjunto. Ele não pretende fazer toda a história do cuidado de si, mas isolar três momentos a ele pertinentes: o "socrático-platônico", a "idade de ouro da cultura de si" (a filosofia helenística e romana) e o "ascetismo cristão", , concentrando-se, assim, na constituição do sujeito por meio das relações entre filosofia e espiritualidade.

Essa ocupação que o sujeito deve ter consigo mesmo mediante um conjunto de práticas, técnicas, procedimentos e recomendações morais - obrigação da espiritualidade - teria sido, segundo o autor, deixada à margem da "história da subjetividade", embora desde há muito tempo já viesse sendo colocada como principal trabalho da atividade filosófica. O cuidado de si foi "esquecido", e esta sua desqualificação se deu em favorecimento do conhecimento de si e de suas técnicas (FOUCAULT, 2011b). Todavia, no pensamento antigo, tal cisão jamais seria possível: filosofia e espiritualidade operariam lado a lado na busca do sujeito pelo acesso à verdade.

\footnotetext{
Chamemos "filosofia" a forma de pensamento que se interroga sobre o que permite ao sujeito ter acesso à verdade, forma de pensamento que tenta determinar as condições e os limites do acesso à verdade. [...] [A] "espiritualidade" [, por sua vez, se refere mais a]o conjunto de buscas, práticas e experiências tais como as purificações, as asceses, as renúncias, as conversões do olhar, as modificações de existência, etc., que constituem, não para o conhecimento, mas para o sujeito, para o ser mesmo do sujeito, o preço a pagar para ter acesso à verdade (FOUCAULT, 2011b, p. 15).
}

Filosofia e espiritualidade refletem então, nos escritos dos autores deste período, o vínculo existente entre os procedimentos do gnôthi seautón e da epiméleia heautoû: a filosofia sempre veio exigindo e requalificando a epiméleia heautoû. Mas, no decorrer de sua historiografia, as

\footnotetext{
${ }^{3}$ Este terceiro momento, o do "ascetismo cristão", de fato, não se conclui neste curso de 1982.
} 
práticas de si foram postas à margem, em relação à centralidade que o gnôthi seautón foi ocupando no desenvolvimento do pensamento ocidental. Nas mais variadas formas de filosofia, o cuidado de si foi convertido numa série de procedimentos inteiramente outros que soam a nós mais como formas de egoísmo, desvinculando-o completamente de sua significação original.

\section{Entre filosofia e espiritualidade: a parrhesía no curso de 1982 (A hermenêutica do sujeito)}

Foucault reconhece a origem da desqualificação da epiméleia heautoû no modo como o problema da verdade passa a ser colocado a partir da filosofia do século XVII, naquilo que ele considerou chamar de momento cartesiano: a partir das Méditations métaphysiques de Descartes (1641), o problema das relações entre sujeito e verdade é proposto a partir de uma requalificação filosófica do gnôthi seáuton, ao pressupor, no princípio da atividade filosófica, que a verdade será acessada somente pela evidência de que o sujeito existe, ao passo que desqualificará a epiméleia heautôิ. Este momento, entretanto, “[...] não se fez no dia em que Descartes colocou a regra da evidência ou descobriu o Cogito" (FOUCAULT, 2011b, p. 26), muito menos se refere única e exclusivamente à filosofia cartesiana, mas ao momento mais geral da Idade Moderna do conhecimento: “[...] entramos na Idade Moderna (quero dizer, a história da verdade entrou em seu período moderno) no dia em que admitimos que o que dá acesso à verdade, as condições segundo as quais o sujeito pode ter acesso à verdade, é o conhecimento e tão somente o conhecimento" (FOUCAULT, 2011b, p. 17-18). A filosofia moderna declara que o sujeito apenas terá acesso à verdade pelo próprio ato do conhecimento e pelas suas regras, ou seja, pelo método. O sujeito, nas suas condições concretas, é capaz da verdade; não há nenhuma modificação necessária a ser operada nele. Foucault admite, no entanto, que o rompimento do diálogo existente desde a Antiguidade entre filosofia e espiritualidade já havia se iniciado muito antes, com a teologia cristã (escolástica); esta, ao introduzir "[...] uma fé cuja vocação é universal, fundava, ao mesmo tempo, o princípio de um sujeito cognoscente em geral, sujeito cognoscente que encontrava em Deus, a um tempo, seu modelo, seu ponto de realização absoluto [...]”, e que reconhecia Nele "[...] seu Criador, assim como, por consequência, seu modelo" (FOUCAULT, 
Autor: A parrhesía na constituição do sujeito ético em M. Foucault: análise dos cursos no Collège de France, 19821983.

2011 b, p. 26) ${ }^{4}$. No cristianismo do fim do século XIII, instaura-se um conflito entre espiritualidade (com seus saberes esotéricos, como a alquimia, por exemplo) e teologia - conflito este que perdurará até o século XVII. Portanto, não foi o surgimento da filosofia e ciência modernas que incidiu unicamente nesta brusca dissociação entre espiritualidade e filosofia. Mesmo na filosofia moderna, não houve um total desprendimento, já que no século XVII, de certo modo, a espiritualidade "retoma" seu espaço no problema do sujeito em seu acesso à verdade; com a noção de "reforma do entendimento" (fim do século XVI e início do XVII), reencontra-se uma exigência de espiritualidade: “[...] o problema do acesso à verdade, em Espinosa, estava ligado, em sua própria formulação, a uma série de exigências que concerniam ao ser mesmo do sujeito" (FOUCAULT, 2011b, p. 27). Em Kant, também, as exigências de espiritualidade não desapareceram, em certo sentido; assim como, em toda a filosofia do século XIX, o conhecimento ainda aparece ligado à exigência de espiritualidade:

E podemos considerar, creio eu, toda a história da filosofia do século XIX como uma espécie de pressão pela qual se tentou repensar as estruturas da espiritualidade no interior de uma filosofia que, desde o cartesianismo, ou em todo caso, desde a filosofia do século XVII, se buscava desprender dessas mesmas estruturas. Donde a situação de hostilidade, profunda aliás, entre todos os filósofos [de] tipo "clássico" - Descartes, Leibniz, etc., todos aqueles que reivindicam aquela tradição - e esta filosofia do século XIX que, com efeito, é uma filosofia que coloca, implicitamente ao menos, a velha questão da espiritualidade e que reencontra, sem dizê-lo, o cuidado com o cuidado de si. (FOUCAULT, 2011b, p. 28).

No campo do saber, ainda reencontraremos determinadas práticas discursivas que, embora pretendam-se o estatuto de "científicas", manterão em sua própria disposição algumas exigências de espiritualidade, tais como no marxismo e na psicanálise (FOUCAULT, 2011a., p. 28-29). Destarte, Foucault retoma a epiméleia heautoû para melhor formular a questão da relação que o sujeito estabelece com a verdade. Veremos que este procedimento do cuidado de si não exclui o gnôthi seautón, posto que sempre apareceram dialogando entre si durante um longo período da historiografia da filosofia. No templo de Apolo em Delfos, este famoso preceito, cujo registro se

\footnotetext{
${ }^{4}$ Há na teologia "a correspondência entre um Deus que tudo conhece e sujeitos capazes de conhecer, sob o amparo da fé é claro [...]" (FOUCAULT, 2011b, p. 26), para que estes tenham o acesso à verdade, que é a divina. Conferir também os estudos de Pierre Hadot acerca da ruptura entre discurso filosófico e modo de vida filosófico na emergência da escolástica medieval, a partir do século XIII (HADOT, 2011, p. 355-380).
} 
encontra no centro da comunidade humana ${ }^{5}$, é inscrito aqui em outro contexto e abordagem, diferente das que posteriormente lhe serão conferidas; surge aí como regra a ser seguida no ato da consulta ao oráculo do templo, como uma exortação de prudência. Vale lembrar que não está sozinho: junto a ele, encontramos também o "medèn ágan" ("nada em demasia") e o "engýa, párà d'áta" ("comprometer-se traz infelicidade"). Emerge, assim, a necessidade de estudar as "práticas de si" ao longo dos séculos, desde o período socrático-platônico até o helenísticoromano ${ }^{6}$.

Da epiméleia heautô̂, por ora, podemos sustentar: a) trata-se de uma atitude do sujeito para consigo mesmo e para com os outros; b) trata, igualmente, de uma atenção, uma conversão do olhar do sujeito para si; e, também, c) designa exercícios e práticas que devem ser desempenhadas pelo sujeito a fim de que este se modifique e, modificando-se, transforme todo seu ethos (FOUCAULT, 2011b, p. 5-6, p. 11-12). Ao incitar os homens a se ocuparem consigo, Sócrates mantém-se num propósito, num posto, numa taxe, que lhe fora confiado pelos deuses; é o mestre do cuidado de si: renunciou vantagens para si próprio a fim de cuidar dos outros. Depreende-se daí que há relações do cuidado com o conhecimento de si, dado que a epiméleia heautoû sempre acompanhou o gnôthi seautón (FOUCAULT, 2011b, p. 9-10):

Parece-me que a noção de epiméleia heautô̂ acompanhou, enquadrou, fundou a necessidade de conhecer-se a si mesmo não apenas no momento de seu surgimento no pensamento, na existência, no personagem de Sócrates. Parece-me que a epiméleia heautoû (o cuidado de si e a regra que lhe era associada) não cessou de constituir um princípio de quase toda a cultura grega, helenística e romana.

Ao analisar o primeiro Alcibíades, Foucault (2011b, p. 37) afirma que "o que está em jogo no diálogo é, pois: qual o eu de que devo ocupar-me a fim de poder, como convém, ocupar-me com os outros a quem devo governar?”. O diálogo se desenvolve no seguinte percurso: aquele que têm algum privilégio estatuário deve ter cuidados consigo para, assim, poder cuidar dos outros; o cuidado de si é a condição para bem governar os outros. A epiméleia heautoû, em

\footnotetext{
${ }^{5} \mathrm{O}$ omphalós, umbigo do mundo, donde a sua importância para os gregos; cf. nota 10 em FOUCAULT, 2011b, p. 20.

${ }^{6}$ A civilização grega arcaica já apontava para determinadas práticas que o sujeito deveria operar em si mesmo. De modo especial, o princípio de que "é preciso ocupar-se consigo mesmo" já se apresenta como uma sentença lacedemônia; Alexândrides, um espartano, quando perguntado sobre o porquê de os lacedemônios confiarem o cuidado de suas terras aos hilotas, responde: confiamos nossa terra aos hilotas para nós nos ocuparmos conosco mesmos (FOUCAULT, 2011b).
} 
Autor: A parrhesía na constituição do sujeito ético em M. Foucault: análise dos cursos no Collège de France, 19821983.

primeiro lugar, aparece vinculada ao exercício do poder, à condição política: entre os privilégios que o sujeito tem até a ação política que ele pretende emerge, nessa intersecção, o cuidado de si. Em segundo lugar, o cuidado de si é necessário porque a educação ateniense é inteiramente deficiente; esta mesma crítica se dirige ao amor (éros) entre homens e rapazes. Alcibíades fora desprezado por seus enamorados, que dele só queriam o corpo; Sócrates, muito pelo contrário, quer algo de mais fundamental em Alcibíades, que é o ser mesmo dele. Enquanto os enamorados de Alcibíades queriam o que ele tinha (o corpo), e os abandonam quando estão "[...] naquela idade crítica em que, precisamente [...] necessitariam de um guia para se formar nessa coisa outra, nova, para a qual não foram de modo algum formados por seu mestre: o exercício da política (FOUCAULT, 2011b, p. 42)", Sócrates quer o que ele é - isto é, o próprio Alcibíades, a sua alma. Em terceiro lugar, é necessário cuidar de si quando se é jovem, quando se está na idade crítica. Em quarto lugar, finalmente, ter ocupações consigo é emergente quando se percebe num estado deplorável de ignorância, numa ausência de saber político (FOUCAULT, 2011b, p. 34-36, p. 42-43).

Embora enraíze-se em práticas bem antigas ${ }^{7}$, essa emergência da epiméleia heautoû, na filosofia, surge certamente com Platão. No Alcibíades, vemos a alma como sujeito e não como substância. O cuidado de si é, assim, o cuidado com a alma (diferente de outras formas tradicionais de cuidado na Grécia clássica, como o médico que cuida do corpo, o pai de família que cuida dos bens da casa, ou ainda os cuidados da erótica). Sócrates, ao contrário dos pretendentes de Alcibíades, atenta-se aos cuidados que Alcibíades terá consigo próprio. Desta forma, Sócrates é o mestre do cuidado de si (FOUCAULT, 2011b, p. 55): "o mestre é aquele que cuida do cuidado que o sujeito tem de si mesmo e que, no amor que tem pelo seu discípulo, encontra a possibilidade de cuidar do cuidado que o discípulo tem com si próprio". Sua mestria é fundada no amor gratuito (FOUCAULT, 2011b, p. 53-55).

O cuidado de si, todavia, não pode ser confundido com o "conhece-te a ti mesmo". A epiméleia heautoû é o "solo" sob o qual se assenta o conhecimento de si - para alcançar a verdade, é exigido ao sujeito que opere mudanças fundamentais em seu ser. A filosofia, portanto, enquanto gnôthi seautón, nunca esteve desvinculada de uma espiritualidade, como epiméleia

\footnotetext{
7 “Que a verdade não possa ser atingida sem certa prática ou certo conjunto de práticas totalmente especificadas que transformam o modo de ser do sujeito, modificam-no tal como está posto, qualificam-no transfigurando-o, é um tema pré-filosófico que deu lugar a numerosos procedimentos mais ou menos ritualizados" (FOUCAULT, 2011b, p. 44).
}

Sapere aude - Belo Horizonte, v. 7 - n. 12, p. 269-288, Jan./Jun. 2016 - ISSN: 2177-6342 
heautô̂, pelo menos desde Sócrates até o limiar da Idade Moderna. O Alcibíades de Platão é, nesse primeiro momento da história do cuidado de si na preocupação filosófica, a introdução geral desta problemática na história da subjetividade, em sua íntima relação com a verdade. Já há alguns séculos mais tarde, dá-se um novo momento na história do cuidado de si: enquanto em Platão o cuidado de si identifica-se ao cuidado com a alma, nos filósofos helenísticos e romanos, o cuidado de si encontrará uma de suas principais formulações na dietética, como um "regime geral", concernindo aos cuidados com o corpo e com a alma. O cuidado de si desenvolverá certa relação com a atividade social (a do pai de família, a do senhor de escravos, etc.: a "econômica"), que se diferirá em cada uma das escolas filosóficas. Distanciando-se de Platão, o cuidado de si não mais estará vinculado a uma erótica, tal como era com Sócrates; a erótica tornar-se-á uma prática individual e inquietante.

A epiméleia heautô̂ assumirá, assim, a principal função da atividade filosófica no período helenístico e romano. Em Epicuro, a filosofia, enquanto cuidado de si assumido por toda duração da vida, comporta a função "terapêutica" - de "therapeúein": "terapia" da alma, numa analogia com cuidados médicos; também em analogia aos cuidados que um servidor presta a seu mestre; ou ainda, ao serviço de culto a uma divindade. O cuidado de si é fundamental para os cínicos, exigência que acompanhava regras a serem seguidas; Demetrius, o cínico, ressalta a importância do sujeito dirigir o olhar para si mesmo. Dentre os estoicos, vemos o cuidado de si como princípio de toda conduta racional; a epiméleia heautoû, traduzido por cura sui, é central em Sêneca e Epicteto. E não apenas entre os filósofos: o cuidado de si assume grande importância como conjunto de práticas disseminadas a toda conduta racional e (por isso) moral; o cuidado de si, deste modo, foi um "fenômeno cultural de conjunto". Também, no cristianismo, o cuidado de si desempenhara um papel fundamental na origem da vida ascética (FOUCAULT, 2011b, p. 10-11). Os séculos I e II de nossa era, período que compreende desde o estoicismo romano, o renascimento da cultura clássica do helenismo, até o início do cristianismo, com Tertuliano e Clemente de Alexandria, é o que Foucault (FOUCAULT, 2011b, p. 75) chama de "idade de ouro" da cultura de si: isto porque a epiméleia heautô̂ assume seu espaço mais que fundamental em todo princípio de conduta moral. Apesar de ter seu aparecimento e "fundamento" (na atividade filosófica) com Sócrates, agora o cuidado de si toma um caráter diferente daquele que antes lhe era atribuído: o cuidado de si passa a ser um princípio geral e 
Autor: A parrhesía na constituição do sujeito ético em M. Foucault: análise dos cursos no Collège de France, 19821983.

incondicional a todos, mas que é dado exclusivamente àqueles que podem ocupar-se de si mesmos - diferente do momento socrático-platônico, no qual o cuidado de si era necessário para os jovens aristocratas, destinados a exercer o poder político; da mesma forma, a finalidade do cuidado de si não será mais conduzir os outros na política, mas dirigir o próprio sujeito na condução de uma vida bela ${ }^{8}$; entre outras, estas são continuidades e rupturas que a "idade de ouro" vem lhe introduzir.

Há, assim, um objetivo de "autofinalização" (FOUCAULT, 2011b, p. 77) no cuidado que o sujeito opera em si; e não será mais somente no conhecimento de si que a epiméleia se apoiará, mas num conjunto mais vasto de exercícios, de práticas de subjetivação: o cuidado de si torna-se "coextensivo" à toda a vida do sujeito. Não mais se toma o cuidado de si somente quando se está na "idade crítica", mas em todo o momento da vida é preciso ter ocupações consigo mesmo (FOUCAULT, 2011b, p. 76-80). Na Carta a Meneceu, Epicuro (2002, p. 21) afirma: "que ninguém hesite em se dedicar à filosofia enquanto jovem, nem se canse de fazê-lo depois de velho, porque ninguém jamais é demasiado velho ou demasiado jovem para alcançar a saúde do espírito". Nesta passagem, vemos um "esboço geral" do modo como o cuidado de si é convertido no período helenístico e romano: deve-se cuidar de si, deve-se filosofar - cuidar de si é filosofar - por toda a vida, pois nunca se é velho, nem jovem demais para ter cuidados com o próprio espírito, com a própria alma: $v v \chi$ ń. Deve-se ter cuidados consigo para se "alcançar a saúde": o cuidado de si é assimilado aos cuidados médicos, assumindo uma função crítica, de cura, terapêutica (therapeúein), e não mais pedagógica.

O filósofo é o mestre do cuidado de si: a função dele é assimilada à do médico, mas ao "médico da alma". Sêneca (2010), em seu Da tranquildadade da alma, apresenta certas "práticas de tipo individual"; neste tratado, vemos Serenus, seu discípulo, após falar de seu "estado de alma", pedir a Sêneca que lhe seja seu "médico da alma", que lhe faça um "diagnóstico, que the dê "conselhos". Já Epicteto funda uma escola; ele é "professor por profissão" e na sua academia acolhe alunos que para lá vão se formar. Os cínicos proferem seus discursos "nas praças públicas", ao "público em geral". O grupo dos Terapeutas se retira de seu meio para ter cuidados

\footnotetext{
${ }^{8}$ A filosofia é o que permite a condução de uma vida bela. Foucault vê que nos gregos antigos não havia uma dissociação da ética e da estética, mas que estas eram inseparáveis uma da outra: disso, a ética é condição da estética. O último Foucault, deste modo, é regularmente caracterizado pelo seu "viés estético", pela "estética da existência" (CANDIOTTO, 2008, p. 87-88). Contudo, havia uma diferença sim entre estas, a saber, a ética e a estética. A busca do sujeito antigo era o bem, considerado como valor supremo, e não o belo (SÊNECA, 2010, p. 17).
} 
com a própria alma (FOUCAULT, 2011b, p. 81-83). Mas, ao mesmo tempo, no discurso que este mestre do cuidado de si, o filósofo, pronuncia, emerge a necessidade da verdade: exige-se a parrhesía - a coragem da verdade, o dizer verdadeiro. Na direção de consciência, uma "ética da palavra", uma "certa maneira de dizer" - a parrhesía - é requerida (FOUCAULT, 2011b, p. 123124). Identifica-se, aí, a necessidade fundamental, na história da ética do sujeito, do franco falar, de dizer-a-verdade 9 . Ao longo do desenvolvimento das práticas de si, emerge uma nova ética, a "da relação verbal com o Outro", centrada no conceito de parrhesía (FOUCAULT, 2011b, p. 148). No curso A hermenêutica do sujeito, Foucault aponta para o problema de seus próximos cursos: exigência da parrhesía, a coragem de dizer a verdade.

\section{Sujeito ético e veridicção: a parrhesía no curso de 1983 (O governo de si e dos outros)}

A exigência de parrhesía, de dizer-a-verdade, aparece no momento em que o mestre do cuidado de si, enquanto diretor de consciência, deve proferir discursos que vão ajudar na constituição do sujeito a ele designado a ser dirigido. Emerge a exigência do franco falar ao filósofo que transmite discursos às pessoas "em geral” nas praças públicas, como ao filósofo que ministra seu ensinamento na escola, ou, ao que enuncia discursos numa comunidade de vida. $\mathrm{E}$ em toda a polis, a parrhesía é exigência daquele que tem o papel de dirigir a conduta dos outros, àquele que enuncia discursos - a condição de uma relação plena e satisfatória, que só o pode ser à medida que se funda, ou enraíza-se, na verdade. É a verdade que deve ser a mediadora de uma relação ética do sujeito para consigo mesmo e para com os outros. A parrhesía é um "dizer tudo": "pân rêma, Parresiázesthai é 'dizer tudo'. O parresiastés é aquele que diz tudo" (FOUCAULT, 2011a, p. 10). Mas a parrhesía é um "dizer tudo" intimamente ligado à verdade ${ }^{10}$ : “dizer tudo da verdade, não ocultar nada da verdade, dizer a verdade sem mascará-la com o que quer que seja" (FOUCAULT, 2011a, p. 11). Foucault inicia sua primeira aula do curso de 1983 (“Aula de 5 de janeiro”), evocando o projeto que acompanhou o seu percurso pensante: o de

\footnotetext{
${ }^{9}$ Há, neste mesmo curso de 1982, um estudo mais amplo do modo como a parrhesía emerge no cuidado que o sujeito tem consigo mesmo, na sua constituição de sujeito ético, sempre relacionado ao Outro. Aqui apenas pontuamos alguns de seus traços mais fundamentais, sob os quais a nossa pesquisa se apoiará. Deste modo, apresentamos a introdução mais geral do cuidado de si na genealogia do sujeito ético para introduzir o problema da parrhesía.

${ }^{10}$ Houve qualificações dadas à parrhesía em sentido pejorativo: como um "dizer tudo" em que "se diz qualquer coisa", em que o parrhesiasta aparece como um "tagarela impenitente" (FOUCAULT, 2011a, p. 10-11).
} 
Autor: A parrhesía na constituição do sujeito ético em M. Foucault: análise dos cursos no Collège de France, 19821983.

fazer "uma história do pensamento" (Idem, 2010b, p. 4), entendendo "pensamento" como uma análise que se ocuparia dos "focos de experiência" de nossa cultura ${ }^{11}$. Deste projeto, a partir da análise da experiência da "loucura" - "como matriz de conhecimento", como "normas de comportamento" e como experiência que define "a constituição de certo modo de ser do sujeito normal, perante e em relação ao sujeito louco" (FOUCAULT, 2010b, p. 5) -, a pesquisa de Foucault pôde se estabelecer em três momentos que o autor identifica, de forma prospectiva, estarem intimamente vinculados entre si: em um primeiro momento, "a formação dos saberes das ciências empíricas dos séculos XVII e XVIII; depois, a genealogia das "matrizes normativas de comportamento"; enfim, um terceiro "eixo", no qual se inquire sobre a "constituição do modo de ser do sujeito" pela análise história da "pragmática de si” (FOUCAULT, 2011a, p. 5-7) ${ }^{12}$. É neste terceiro momento que a pesquisa foucaultiana apresenta a parrhesia como forma de veridicção que se estabelece na constituição do ethos do sujeito. Surgido, como vimos, no desdobramento das pesquisas que darão origem ao curso de 1982 e que constituem o material fulcral para $H S I I$ e HS III, o problema da parrhesía tornar-se-á central nos cursos de 1983 e 1984 - respectivamente, Le gouvernement de soi e des autres e Le gouvernement de soi e des autres II: le courage de la vérité. Neste último, Foucault retoma a análise prospectiva do objeto de sua pesquisa, mas de forma um tanto diferente daquela anteriormente evocada em L'usage des plaisirs:

A partir de que práticas e através de que tipos de discursos se procurou dizer a verdade sobre o sujeito? Assim: a partir de quais práticas, através de que tipos de discursos se tentou dizer a verdade sobre o sujeito louco ou sobre o sujeito delinquente? A partir de que práticas discursivas se constituiu, como objeto de saber possível, o sujeito falante, o sujeito trabalhante, o sujeito vivente? (FOUCAULT, 2011a, p. 5).

A parrhesía surge no pensamento tardio de Foucault, como "objeto privilegiado de estudo", numa articulação de interesses que possibilitou ao filósofo "[...] reatravessar o campo da política (problema da estruturação das condutas dos demais: como governar os outros?), depois de ter tentado isolar e definir um campo ético (problema da estruturação da relação consigo mesmo: como governar a si mesmo?)" (GROS, 2013, p. 155). É na relação entre o governo de si

\footnotetext{
${ }^{11}$ Na primeira aula do curso de 1984, “Aula de $1^{\circ}$ de fevereiro de 1984" (FOUCAULT, 2011a, p. 10), também podese encontrar, de maneira "mais breve", o projeto de Foucault de fazer "uma história do pensamento": "[...] estudar as relações entre verdade, poder e sujeito, sem nunca reduzi-las umas às outras".

${ }^{12}$ Cf., igualmente, a análise realizada por ARAÚJO (2008), na determinação destes eixos, ou matrizes de análise, que organizam e, de certa forma, dividem as fases do pensamento do autor.
}

Sapere aude - Belo Horizonte, v. 7 - n. 12, p. 269-288, Jan./Jun. 2016 - ISSN: 2177-6342 
e o governo dos outros que emerge a necessidade da parrhesía. Mas a parrhesía difere-se de tantos outros "governos" que pretendem dirigir a conduta de outros, como o governo pastoral cristão de direção de consciência, de confissão, e a retórica dos sofistas, como outras tantas formas de dirigir os outros pelo discurso que se opõe à parrhesía. Para Foucault, parece ser um estudo mais interessante das relações entre subjetividade e verdade, não o modo como o discurso pretende dizer - e diz - a verdade sobre o sujeito, mas sim o modo "[...] do discurso de verdade que o sujeito é capaz de dizer sobre si mesmo, [sob] algumas formas culturalmente reconhecidas e típicas, por exemplo a confissão e o exame de consciência” (FOUCAULT, 2011a, p. 5).

Este problema levou Foucault, nos anos anteriores, a uma história das práticas do dizera-verdade sobre si mesmo. Mas a necessidade do sujeito dizer-a-verdade sobre si deve ser imputada às práticas de si da Antiguidade. Foi, portanto, voltando seu olhar para a Antiguidade que Foucault viu emergir a necessidade do sujeito dizer-a-verdade sobre si. Foi antes mesmo do cristianismo institucionalizar a confissão, como desenvolver todo o seu poder pastoral, na intersecção do sujeito consigo mesmo e com o outro - " [...] o outro que escuta, o outro que incentiva a falar e que fala ele próprio" (FOUCAULT, 2011a, p. 6) - que a prática do "dizer verdadeiro" tomou seu lugar na "história da subjetividade". O estudo da parrhesía na Antiguidade é, deste modo, uma "pré-história" dessas práticas do "dizer verdadeiro", que se desenvolverão, mais tarde, em formas célebres de nossa cultura: “[...] o penitente e seu confessor, o dirigido e o diretor de consciência, o doente e o psiquiatra, o paciente e o psicanalista (FOUCAULT, 2011a, p. 9).

Em sua etimologia, a palavra parrhesía significa "franqueza": "dizer tudo" sem nada ocultar, "falar francamente", "dizer a verdade". O parresiasta é aquele que tem a coragem de dizer tudo, ele diz a verdade e faz desta sua prática o seu ethos de sujeito. A parrhesía é uma "ética da palavra". "Parrhesía é a abertura do coração, é a necessidade, entre os pares, de nada esconder um ao outro do que pensam e se falar francamente” (FOUCAULT, 2011b, p. 124). O parresiasta toma essa sua "abertura", sua "coragem", de "dizer a verdade" na relação que tem consigo mesmo e com os outros. A parrhesía se "concretiza" efetivamente quando as enunciações proferidas “[...] se tornam matrizes práticas de ação e vêm em socorro do sujeito numa situação concreta [...]" (CANDIOTTO, 2013, p. 141). Por isso, a parrhesía difere-se de um discurso interesseiro, bajulador, interessado na "circunstancialidade": porque ela atua na 
Autor: A parrhesía na constituição do sujeito ético em M. Foucault: análise dos cursos no Collège de France, 19821983.

constituição do sujeito ético. "O diretor de existência antiga se caracteriza, com efeito, por uma tomada da palavra direta, franca e que faz valer, para autenticar a verdade do que ele defende, sua própria conduta: a verdade daquilo que adianto explode em meus atos" (GROS, 2013, p. 156157). A fala do parrhesiasta, no entanto, por ser verdadeira, franca, é perigosa: é a imagem da condenação de Sócrates, como também a dos cínicos mendigando na cidade - donde a filosofia foi tomada como discurso perigoso à ordem social, ou mesmo "apartado" de uma relação "de verdade" com os outros.

Mas, do que trata precisamente esta certa maneira de dizer a verdade que Foucault aponta estar no cerne da separação entre o discurso verdadeiro do parresiasta e o discurso que se pretende verdade do retórico? Em sua análise da Vida de Díon, de Plutarco, identificará que, entre o sobrinho do tirano Dionísio e Platão, há maneiras diversas de dizer a verdade; cita Foucault sobre Díon: "Ele era praticamente o único cuja parresía o tirano suportava e a quem deixava dizer ousadamente o que lhe vinha à mente" (FOUCAULT, 2010b, p. 49). A parrhesía de Díon está protegida por suas relações de parentesco com o tirano de Siracusa. Todavia, aqui temos a mesma fórmula, ou o mesmo modo de ação, identificado por Foucault em uma simples frase: "Um homem se ergue diante de um tirano e lhe diz a verdade" (FOUCAULT, 2010b, p. 49). Correta em sua aplicação a Platão, correta em sua aplicação a Díon também; mas que não constitui o distintivo primeiro que irá separar as formas próprias da parrhesía das outras estratégias de enunciação, que também primam pelo convencimento. No caso das estratégias de demonstração, por exemplo, embora estas se exerçam a partir de um dizer verdadeiro ou, se quisermos, de um dizer racional, e possam mesmo estar presentes no discurso parresiástico como no caso do discurso de Galileu perante o tribunal do Santo Ofício, em 1633 -, não são seu elemento originário e constituidor. Assim como no discurso pedagógico (por exemplo, na ironia e na maiêutica socráticas) a função de dizer a verdade é secundária em relação à finalidade à qual se quer alcançar - ou seja, que aquele que não sabe saber consiga formular o seu próprio discurso de verdade. Foucault dirá mesmo que, neste aspecto, a parrhesía é, ao final, uma verdadeira antiironia, por todo o elemento de brutalidade e de violência ou, ao menos, de abrupção, que o cerca:

Na parresía, ao contrário, [...] quem diz a verdade lança a verdade na cara desse interlocutor, uma verdade tão violenta, tão abrupta, dita de maneira tão cortante e tão definitiva, que o outro em frente não pode fazer mais que calar-se, ou sufocar de furor,

Sapere aude - Belo Horizonte, v. 7 - n. 12, p. 269-288, Jan./Jun. 2016 - ISSN: 2177-6342 
ou ainda passar a um registro totalmente diferente, que é, no caso de Dionísio ante Platão, a tentativa de assassinato (FOUCAULT, 2010b, p. 54).

Também a erística, a "arte da controvérsia e do debate" (FOUCAULT, 2010b, p. 57, nota 24), embora comporte igualmente certa relação agonística entre dois personagens que lutam em torno da verdade, tão prontamente apresentada, é logo descartada pelo autor: “[...] não creio que a parresía faça parte de uma arte da discussão, na medida em que a arte da discussão permite fazer triunfar o que acreditamos ser verdadeiro [...]" e, desta forma, substitui a vitória da verdade formulada pelo discurso por outra vitória, "[...] a vitória da violência, da violência pura" (FOUCAULT, 2010b, p. 54-55, grifo nosso). Por fim, resta ainda analisar as estratégias da persuasão inscritas na arte da retórica; neste aspecto, Foucault insiste que as relações são de ordem complexa, uma vez que, e embora a retórica não trate de um modo específico de dizer a verdade, pertencendo mais à arte ou à "técnica de dispor os elementos do discurso a fim de persuadir" (FOUCAULT, 2010b, p. 53), pode-se afirmar com clareza que a parrhesía não trata apenas de persuadir - esta não é especificamente a função da parrhesía. Dessa forma, é possível afirmar que, mesmo a retórica podendo conter elementos que tragam em seu bojo um dizer verdadeiro, e, de forma análoga, que a parresía possa utilizar-se dos elementos da persuasão e da arte da retórica em determinados momentos, uma escapa à outra no que tange ao seu aspecto fundamental - na parresía, o objetivo final, enunciar a verdade, não pode estar preso ao resultado esperado de uma persuasão, ou seja, o convencimento; aliás, o modo mesmo de enunciá-la poderá ter o efeito inverso do resultado esperado no âmbito comum da retórica. Tem-se aqui, portanto, “[...] algo que é da ordem do desafio, [...] da ordem do insulto, da crítica" (FOUCAULT, 2010b, p. 53); elemento este que se abre, desta forma, àquilo que poderá caracterizar primeiramente a parrhesía: o risco que se corre em enunciar a verdade, ou, dito de modo outro, a coragem de dizer a verdade.

Tal é, certamente, uma das marcas mais evidentes do discurso parresiástico, a saber, o risco que se corre em relação à própria vida, ou pelo menos a possibilidade de arriscar-se até a perca da própria vida - "quaisquer que sejam as formas utilizadas por esta parresía quando se recorre a ela, sempre há parresía quando o dizer-a-verdade se diz em condições tais que o fato de dizer a verdade, e o fato de tê-la dito, vai ou pode ou deve acarretar consequências custosas para os que disseram a verdade" (FOUCAULT, 2010b, p. 55). Dizer a verdade acarreta, portanto, um 
Autor: A parrhesía na constituição do sujeito ético em M. Foucault: análise dos cursos no Collège de France, 19821983.

risco para quem a enuncia, e este risco é precisamente aquilo que vincula o locutor à sua própria verdade enunciada e ao fato do que o que diz é a verdade (ou, ao menos, que naquele momento estará convencido de que o que diz, o diz precisamente por ser a verdade que precisa ser enunciada). "Dizer a verdade na presença de Dionísio", segundo Foucault, “[...] é abrir para quem dizia a verdade um certo espaço de risco, é abrir um perigo, é abrir um perigo em que a própria existência do locutor vai estar em jogo, e é isso que constitui a parresía" (FOUCAULT, 2010b, p. 55).

\section{CONSIDERAÇÕES FINAIS}

Risco da verdade, em primeiro lugar; coragem da verdade que vincula o sujeito à verdade que profere. Mas também possibilidade de exercer sua cidadania dentro do jogo das instituições democráticas no interior da cidade, onde a possibilidade da fala (demokratía) e a igualdade de fala (isegoría) devem vir acompanhadas da liberdade de fala que se fundamenta na probidade de um dizer legítimo e verdadeiro. Este é o problema que acompanhará as relações entre a democracia e a parrhesía no interior da dynasteía ateniense, de Péricles a Platão, e que se mostrarão completamente distorcidas ao final do século IV, quando da crítica platônica ao "mau" uso da liberdade de fala no cerne da experiência democrática.

A prática da parrhesía supõe o engajamento daquele que a pratica: o parrhesiasta deve fazer a verdade vir à tona em sua própria vida: ele é um sujeito que tem no dizer verdadeiro a sua verdade mais fundamental e, por isso, escandalosa. Pelo cuidado que o sujeito tem consigo mesmo, ele converterá sua vida na prática da parrhesía, do "dizer verdadeiro", da coragem da verdade; pela "coragem" que o sujeito tem de dizer a verdade, a transformação de seu ethos será efetuada por meio dos jogos de veridicção efetuados no interior dos procedimentos ético-morais de autossubjetivação. Tomada desta forma, a análise do discurso parresiástico, em Foucault, pode ser tomada como um diagnóstico presente, como lembra Ernani Chaves, papel que o próprio autor imputa à filosofia, logo na primeira aula do curso de 1983 (CHAVES, 2013, p. 1213; 21-22), e que repercutirá, da seguinte forma, em sua reflexão sobre a vinculação entre dizer verdadeiro e experiência democrática: 
Pois bem, numa época, a nossa, em que se gosta tanto de colocar os problemas da democracia em termos de distribuição do poder, de autonomia de cada um no exercício do poder, em termos de transparência e de opacidade, de relação entre sociedade civil e Estado, creio que talvez seja bom recordar essa velha questão, contemporânea do próprio funcionamento da democracia ateniense e das suas crises, a saber, a questão do discurso verdadeiro e da cesura necessária, indispensável e frágil que o discurso verdadeiro não pode deixar de introduzir numa democracia, uma democracia que ao mesmo tempo torna possível esse discurso verdadeiro e o ameaça sem cessar (FOUCAULT, 2010b, p. 170).

Se a parrhesía é, portanto, a condição para o bom governo da polis - pois é obrigação do bom governante "falar francamente" -, a veridicção é, também ela, uma exigência do sujeito ético na relação consigo mesmo e com os outros. $\mathrm{O}$ acesso à verdade se converte, então, na razão fundamental pela qual o sujeito estabelece um conjunto de práticas que visam sua própria metamorphé, sua trans-formação, o que seria, em última análise, o télos de seu ethos (FOUCAULT, 2011b).

Tal olhar sobre a Antiguidade - divisá-la como duplo necessário para a crítica de nosso próprio - deveria permitir, igualmente, redescobrir as práticas de si (e a ascética, de uma forma mais genérica), em seu papel de possibilitar ao sujeito uma autoconstituição ética - ou, em termos do autor, uma autopoiese - que lhe permita, assim, “[...] se elaborar, se transformar e atingir um certo modo de ser" (FOUCAULT, 2010a, p. 265) e, ao mesmo tempo, capacitá-lo para a verdade. O "retorno" aos gregos seria, assim, um "[...] redesdobramento final da figura de Sócrates como 'parrhesiasta', irmão um instante sonhado, duplo sorridente" (FOUCAULT, 2011a, p. 155).

A filosofia, aqui, ocupa lugar privilegiado: como articuladora entre vida e verdade: ela exige todo um trabalho do sujeito sobre si mesmo, para que, pela ocupação de si, o sujeito possa converter sua vida à verdade; afinal, “o que é a filosofia senão uma maneira de refletir, não exatamente sobre o que é verdadeiro e sobre o que é falso, mas sobre nossa relação com a verdade?" (FOUCAULT, 2000, p. 305). Todavia, se pela ocupação de si a vida é capaz de se converter à verdade, para fazer dela seu próprio modo de ser, é pela parrhesía que a vida se converte em verdade (GROS, 2013). 


\section{REFERÊNCIAS}

ARAÚJO, Inês Lacerda. Foucault e a crítica do sujeito. 2. ed. Curitiba: Ed. UFPR, 2008.

CANDIOTTO, Cesar. Foucault e a crítica da verdade. 2. ed. Belo Horizonte: Autêntica; Curitiba: Champagnat, 2013.

CANDIOTTO, Cesar. Subjetividade e verdade no último Foucault. Trans/Form/Ação (UNESP. Marília. Impresso), v. 31, p. 87-103, 2008.

CHAVES, Ernani. Michel Foucault e a verdade cínica. Campinas: PHI, 2013.

EPICURO. Carta sobre a felicidade (a Meneceu). Tradução, apres. Álvaro Lorencini e Enzo Del Carratore. São Paulo: UNESP, 2002.

FOUCAULT, Michel. A coragem da verdade: o governo de si e dos outros II: curso dado no Collège de France (1983-1984). Ed. Frédéric Gros, dir. François Ewald e Alessandro Fontana. Tradução Eduardo Brandão. São Paulo: WMF Martins Fontes, 2011a.

FOUCAULT, Michel. A hermenêutica do sujeito: curso dado no Collège de France (19811982). Ed. Frédéric Gros, dir. François Ewald e Alessandro Fontana. Tradução Márcio Alves da Fonseca, Salma Tannus Muchail. 3. ed. São Paulo: WMF Martins Fontes, 2011b.

FOUCAULT, Michel. Ditos e escritos, II: arqueologia das ciências e história dos sistemas de pensamento. Org. Manoel B. Motta; Tradução Elisa Monteiro. Rio de Janeiro: Forense Universitária, 2000.

FOUCAULT, Michel. Ditos e escritos, V: ética, sexualidade, política. Org. Manoel B. Motta; Tradução Elisa Monteiro, Inês A. D. Barbosa. 2. ed. Rio de Janeiro: Forense Universitária, 2010a.

FOUCAULT, Michel. Ditos e escritos, X: filosofia, diagnóstico do presente e verdade. Org., rev. Manoel B. Motta; Tradução Abner Chiquieri. Rio de Janeiro: Forense Universitária, 2014.

FOUCAULT, Michel. História da sexualidade 2: O uso dos prazeres. Tradução Maria Thereza C. Albuquerque; rev. José Augusto G. Albuquerque. São Paulo: Paz e Terra, 2014c.

FOUCAULT, Michel. O governo de si e dos outros: curso dado no Collège de France (19821983). Ed. Frédéric Gros, dir. François Ewald e Alessandro Fontana. Tradução Eduardo Brandão. São Paulo: WMF Martins Fontes, 2010b.

FOUCAULT, Michel. Resumo dos cursos do Collège de France (1970-1982). Tradução Andréa Daher; cons. Roberto Machado. Rio de Janeiro: Jorge Zahar, 1997, p. 87-97. 
FOUCAULT, Michel. Microfísica do poder. Org., int., rev. Roberto Machado. 25. ed. São Paulo: Graal, 2012.

GROS, Frédéric (org.); ARTIÈRES, Philippe [et all]. Foucault: a coragem da verdade. Tradução Marcos Marcionilo; pref. Salma Tannus Muchail. São Paulo: Parábola, 2013 (Episteme; 1).

GROS, Frédéric. Situação do curso. In: FOUCAULT. A hermenêutica do sujeito: curso dado no Collège de France (1981-1982). São Paulo: WMF Martins Fontes, 2011.

HADOT, Pierre. O que é a filosofia antiga? Tradução Dion Davi Macedo. 5. ed. São Paulo: Loyola, 2011.

MACHADO, Roberto (org.). Introdução: por uma genealogia do poder. In: FOUCAULT, Michel. Microfísica do poder. 25. ed. São Paulo: Graal, 2012, p. 7-34.

SÊNECA, Lúcio Anneo. Da vida retirada; Da tranquilidade da alma; Da felicidade. Tradução Lúcia Sá Rebello e Ellen Itanajara Neves Vranas. Porto Alegre: L\&PM, 2010. 